\title{
Psychogenic orofacial pain: literature review, development of a diagnostic questionnaire and three cases report.
}

\section{Dor psicogênica orofacial: revisão da literatura, desenvolvimento de um questionário diagnóstico e relato de três casos.}

Artigo

Original

\author{
Omar Franklin Molina ${ }^{1}$ \\ Zeila Coelho Santos ${ }^{2}$ \\ Natalia de Paula e Silva ${ }^{3}$ \\ Karla Regina Gama ${ }^{4}$ \\ Rogério Ferreira Marchezan ${ }^{5}$ \\ Sérgio Elias Cury ${ }^{6}$ \\ Jamil Elias Dib ${ }^{7}$
}

Original

Paper

Recebido em 08/2011

Aprovado em $08 / 2012$

\author{
Key words \\ Headache \\ Psychogenic Pain \\ Depression
}

Questionnaire

\section{Abstract}

Objectives: Review the literature on psychogenic face or head pain, develop a diagnostic questionnaire for psychogenic head and face pain and present three clinical cases presenting psychogenic pain. Material and Methods: Review of 18 papers on psychogenic pain to develop a diagnostic questionnaire with questions to be answered by patients that presented these three clinical cases. Results: The common things observed in three patients presenting psychogenic pain were higher scores in bruxing behavior, depression, somatization, severe pain and the presence of psychic conflict. Conclusions: Various types of other face and headaches occur in subjects with psychogenic face and head pain. Psychogenic pain individuals usually present severe pain associated with depression. Psychic conflict, somatization and depression are usually associated with psychogenic pain.

\section{Resumo}

Objetivos: Revisar a literatura sobre dor psicogênica na face ou na cabeça, desenvolver um questionário diagnóstico para dor psicogênica nessas regiões e apresentar três casos clínicos com esse distúrbio. Materiais e Métodos: Revisão de 18 artigos, a maioria relacionada com dor psicogênica, elaboramos questões relacionadas com esse distúrbio que os indivíduos afetados ou não poderiam responder $e$ apresentamos e discutimos três casos clínicos com esse distúrbio. Resultados: Achados comuns observados em três pacientes com dor psicogênica foram bruxismo destrutivo e valores altos em depressão, somatização, dor severa e presença de conflito psíquico.Conclusões: Vários tipos de dores faciais e na cabeça ocorrem em individuos com dor psicogênica na face ou na cabeça, estes indivíduos apresentam usualmente dor severa associada com depressão e conflito psíquico. Somatização e depressão estão associados com a dor psicogênica.

\section{Palavras-chave}

Dor de cabeça

Dor Psicogênica

Depressão

Questionário

\footnotetext{
${ }^{1}$ Master of Sciences (UFSC-SC), PA (AES, Chicago, USA), Post Doctoral in Orofacial Pain (Harvard University, USA), Ex Research Associate University of Texas, San Antonio, USA, Professor of Orofacial Pain UNIRG-TO, Brazil.

${ }^{2}$ Master of Sciences, Professor of Orthodontics and Orofacial Pain UNIRG-TO

${ }^{3}$ Nursing Specialist, UNIRG-TO

${ }^{4}$ Speech Therapist, Language Specialists CEFAC, MDS in Education and Psychoanalysis, Speech Therapy Professor UNIRG-TO.

${ }^{5}$ MDS in Cognitive Psychology, Vice-Dean for Student Affairs UNIRG-TO

${ }^{6}$ MDS, Ph.D in Oral Pathology (USP), Professor of Oral Pathology UNIFOA, Volta Redonda, RJ.

${ }^{7}$ MDS (Public Health), Specialist in Oral Surgery UFPEL, Professor of Oral Surgery, UNIRG-TO.
} 
inherent difficulties to understand and diagnose psychogenic pain, it is believed that among

\subsection{Definition of pain}

Pain is a subjective and complex phenomenon with sensory, emotional, behavioral and cognitive components and the International Association for the Study of Pain defines pain as "an unpleasant sensory and emotional experience associated with actual or potential tissue damage, or described in terms of such damage (1). Pain is one of the commonest symptoms encountered in clinical practice and the head is a frequent site of pain. Headache is an experience of everyday occurrence, from which almost everybody suffers on some occasion and its significance will vary from the serious to the trivial (2). Chronic facial pain is an important health problem. It is impossible to measure the extent of distress that it causes patients and those who care for them, but society suffers as a consequence of the disability, loss of employment, litigation, compensation and costs of treatment (1). Patients with chronic facial pain have almost universally had negative experiences of treatment: Surgery has often failed, drugs have not worked, and numerous investigations have given normal results. In many chronic facial pain patients, the symptom has been present for an average of four years before the patient attended a pain clinic (1). Experiences of pain are difficult to describe and it is not surprising that unusual and idiosyncratic attempts may be made by a patient to communicate what he feels. The description will depend upon the patient's verbal facility, the communication between patient and doctor and the patient's personality traits, quite apart from the quality of pain being experience (2).

\subsection{Psychogenic pain}

Psychogenic regional pain is a term used for "pain that patients feel in a region of the body where no peripheral cause can be found and is psychogenic in its evocation" (3). Region refers here to the part where pain is most prominently felt. Psychogenic pain experience equally prominently in two or more regions would be described as "multiple" (3). Because of the chronic orofacial pain patients there remains a large group of patients presenting with major management problems for many doctors in many specialties. Lack of dialogue between dentists and doctors, and the gap in dental and medical knowledge, further contribute to the problem (1). Psychogenic symptoms are ubiquitous, an area dealt with in all specialties in medicine. From a psychiatric viewpoint, psychogenic symptoms can be classified as somatoform disorders, factitious disorders or malingering (4). Somatoform disorders is a especial category in which symptoms are not consciously produced, and include conversion disorder and psychogenic pain (4).

Ruden (5), uses the terms "Complex Psychogenic Pain" to denote a puzzling pain picture that is not explained by standard pain models. Pain is often non anatomical in distribution, is associated with somatosensory changes, is co-morbid with psychological problems and presents difficulties for treatment. A psychogenic headache is head pain that arises in the absence of a peripheral pain-inducing mechanism without demonstrable organic cause (6).

\subsection{Possible etiologic factors:}

Even in the field of psychology/psychiatry, many etiologies and psychodynamics have been related to the development of psychogenic pain. In this regard, one investigation (7) defends the point of view that patients with an increased tendency to react to stress, adverse life events and psychopathological disorders are vulnerable to chronic idiopathic facial pain. The family background is also important and illness in some families, and pain in particular, tends to be regarded as of especial emotional significance. The source of this may be an emotionally manipulative parent. It may be that whenever the mother, say, has a headache, her relatives are expected to pay her a great deal of attention with the result that the child soon learns to adopt the same approach. The child may have a familial tendency to headache of some kind, but will come to use the symptom in an emotional way and always feel that insufficient attention is given to it by others (2). Rejected children who experience pain 
and distress in which their parents take little interest may subsequently tend to complain excessively in an attempt to gain attention and for fear of being unnoticed. In addition, as in the case of depression, pain may sometimes be a symptom equivalent for anxiety and for other emotional conflicts and there are three ways whereby psychological factors can evoke pain: by psychogenic magnification of physical pain, by emotional stress creating muscle tension and producing muscular pain, and more specific regional pain produced by hysterical mechanism or by anxiety (2).

Engels (8), a prominent psychiatrist, researcher and pioneer in the field of psychogenic pain described most mechanisms associated to psychogenic pain in the "pain prone patient" and summarized the characteristic of the individual which is prone to suffer from psychogenic pain:

1. A prominence of conscious or unconscious guilt in which pain serves as a relatively satisfactory means of atonement. When guilt predominates, aggressive impulses are not expressed.

2. The patient has a history of suffering, of many defeats and intolerance for success.

3. Presence of a strong aggressive drive which is not fulfilled, pain being experienced instead.

4. Development of pain as a replacement for a loss at times when a relationship is threatened or loss. In such individual the location of pain is determined by unconscious identification with a love object;

5. He or she reports stressful life events at the time the pain develops. Such stresses seem to involve an actual or threatened object loss which mobilizes feelings of helplessness and hopelessness.

6. Presence of a range of depressive affect varying from feeling helpless to cope with pain/aggression to feelings of loss and grief after deaths or separations of significant others.
Some psychiatrists consider conscious conflict and the patient's difficulties to cope with aggressive drives to be the main cause in individuals with psychogenic migraine (9). A psychogenic headache is head pain that arises in the absence of a peripheral pain-inducing mechanism and without demonstrable organic cause (6). Anxiety in many patients can be converted into a somatic symptoms such as headache and when the conversion is complete, anxiety is not observed clinically (6). Thus, anxiety and tension states have been proposed as the basis of psychogenic headache and conflict which centers on the inability of the patient to adequately express feelings of resentment and hostility. Such feelings are turn inward and may appear as depression and or a muscle contraction headache. Adler and colleagues (10) based on the review of Engel's studies and analysis of subgroups with and without pain, concluded that histories of child sexual abuse, important object loss, presence of a submissive parent and deflection of aggression into the self, were important etiologic factors in the development of psychogenic pain. Violon (11), assessed individuals with intractable facial pain and observed that psychogenic pain started during or after depression, most patients had been affectively deprived in infancy and frequent previous emotional stresses had preceded the onset of psychogenic pain.

\subsection{Psychodynamic factors and personality}

Psychogenic pain is encoded during a traumatizing event where the individual cannot behaviorally express the emotional content of the event. Such encoding occurs during the emotional experience of defensive fury or fear. The situation is perceived as inescapable, hopeless and traumatizing and is associated with the inability to take responsive action (5). Because in one study, significantly more patients with psychogenic pain had previous experience of pain, according to learning theory, the traumatizing situation may have conditioned such individuals to react with pain to minor bodily discomforts (3). Studies evaluating the relationship between psychogenic pain and personality are rare if 
not inexistent. However, in one investigation (3), most psychogenic pain individuals could be characterized as passive dependent, compulsive and passive-aggressive.

\subsection{Clinical characteristics and diagnosis}

Recent studies have emphasized the difficulties faced by primary, secondary and even tertiary care dental practitioners in diagnosing orofacial psychogenic pain. Because such difficulties may lead to inadequate treatment, it is imperative that some unexplained orofacial pains can be diagnosed at the outset to differentiate them from orofacial pain conditions of known etiology so as to optimize proper diagnosis, referral and management (12). Some investigators have also shown that a diagnosis of unexplained orofacial pain is reached only after numerous clinicians from various specialties have seen the patient to exclude an organic cause (13). It the last few years, somatization and even hysteria have been associated with psychogenic pain and one study (2) contends that a positive diagnosis of hysteria may be complex and will depend upon a psychiatric assessment from which relevant psychogenesis and evidence of conversion involving the translation of emotional problems to a physical complaint, an unconscious and complex neurotic mechanism, rather than a means of manipulating others can be observed (2). Patients suffering from psychogenic headache may appear calm and relaxed while describing the presence of severe disabling pain (7).

Lim (9) summarized a set of diagnostic clues for psychogenic pain:

1. There is no clear cut onset, pain is poorly localized, it may occur in multiple sites and extends over an increasing area;

2. Pain varies with changes in the patients' moods;

3. Pain is not relieved by analgesic medication, but anti-anxiety and antidepressant drugs may prove useful and relieve the pain significantly;

4. Pain does not disturb the patient from sleep.
5. Neurotic symptoms and/or personality disorders, may be observed.

\subsection{Secondary gains}

Many conscious or unconscious secondary gains may be obtained from the pain:

1. Aggresive trends may not be expressed as they may be displaced inwards (Guilt atonement);

2. Anxiety may be dissipated and channeled to a bodily symptom (displacement);

3. Pain may be used as a manipulative tool to induce guilt in others;

4. The symptom may be used to dissipate guilt and the pain is chosen instead;

5. Pain may be a means to keep important ties with significant others.

\subsection{Treatment}

Patients with conversion disorder commonly demonstrate physiological, psychological and medication hypersensitivity which provides an additional clue for the presence of a psychiatric disorder. Thus, psychological and or psychiatric treatment may be the therapy of choice (14). Antidepressants are the most successful and widely evaluated drugs used to treat these types of psychogenic facial pains and their benefit seem to be independent of any antidepressant action. Amitryptiline is the antidepressant favored by most clinicians in the field (1) and one study (15) indicates that antidepressants are prescribed in cases of somatoform disorders and psychogenic pain as such drugs have an analgesic effect above that of placebo. Occasionally, rapid relief of psychogenic headache can be obtained after locating an emotional conflict which is then resolved by discussion, and this approach, although time consuming, is always a useful aim. Additionally, counseling the patient about their life stresses and their vulnerability for headaches and other pains may raise the patients' threshold for pain (2). 
Because psychogenic pain is relatively frequent in the chronic pain setting, and many aspects of such disorder are relatively unknown, the goals of this study are threefold:

1. Review the literature on psychogenic facial/headache pain;

2. Develop and present a diagnostic questionnaire for psychogenic pain;

3. Report three recently evaluated clinical cases presenting with psychogenic pain.

\section{Material and methods}

In order to carry out the current investigation we selected some specific keywords including psychogenic pain, psychogenic headache and psychogenic facial pain. Then, we entered these terms into www.google.com as the only source of electronic search so as to get relevant papers on the field of psychogenic pain, specifically orofacial pain and or headache. Based on our research criteria, we found 18 papers which could assist us in conducting the current project. Such papers retrieved from the current literature presented as main tittles: psychogenic pain, psychogenic pain and the pain prone patient, the onset of facial pain and psychiatric/psychological aspects of pain. These papers were identified, copied and stored in an especial folder. Following careful reading and review of these 18 papers, we identified many key long phrases discussing key aspects of psychogenic pain including characteristics, emotional and psychological aspects, type of psychological conflicts, family antecedents, depression, somatization, guilt, rage and resentment. Such key characteristics associated with psychogenic pain were summarized in short phrases which could be responded by any patient (never, rarely, occasionally, frequently, always), which could enable the clinician or specialist to gather in depth information about psychogenic pain. We reasoned that 18 papers would be sufficient to provide a wide range of information including emotional, psychological, therapeutic and diagnostic aspects of psychogenic pain. Such information could be summarized in short and simple phrases becoming a useful readable, comprehensive, self-responded instrument to assess psychogenic pain.

Follows some typical statements found in the papers about psychogenic pain and how they were transformed into simple and understandable questions to be answered by the patients in a clinical setting:

Phrase 1: In a state of undischarged tension, there is a heighten irritability and a chronic readiness for discharge.

Item 1: Before the onset of my pain, I was very anxious and tense, almost ready to discharge.

Phrase 2: A person who is struggling with a repressed desire for passive satisfaction and the need to be taken care of, will seize upon an illness.

Item 2: Before becoming sick or with pain, I had a secret desire to be taken care of.

Phrase 3: Some psychogenic pain patients have a proclivity for pain, to protest and seek painful situations.

Item 3: I like to protest, to be the victim and have a tendency for pain.

Phrase 4: Patients with conversion disorders commonly demonstrate physiological and psychological tendencies characterized by drugs unusual side effects.

Item 4: There are usually many side effects with the drugs doctors have prescribed to me.

Phrase 5: The source of anxiety may be the patient inability to adequately express feelings of resentment and hostility which are then turned inward.

Item 5: It is very difficult for me to express my rage, hate and resentment

Phrase 6: In hypochondria, the preoccupation is not with the symptoms, but with the meaning of symptoms.

Item 6: I am always worried with minor sensations in the body and with the meaning of symptoms.

Once we summarized a set of 70 diagnostic items in the instrument, ordered by the frequency of each event (never, 
rarely, occasionally, frequently, always), we reviewed the questionnaire in order to find repeated items, those that inquired about the same subject and/or that were too long and/or confusing to be answered by the patient. Such questions were deleted or reformulated. At the end of such procedure, 52 questions were considered consistent, clear and precise to be included in the questionnaire. In a second stage, such questionnaire will be used in a sample of Craniomandibular disorder individuals with pain, in those with psychogenic pain and in controls with no pain. We hope that by comparing some specific variables (yet to be determined) in different samples, the instrument can be validated or at least be useful for clinical and research purposes.

If such questionnaire is applied in a sample of craniomandibular disorders, in a group of psychogenic craniofacial pain individuals and controls, different inter-group results are to be expected regarding some specific variables including scores in anxiety, depression, somatization, dependency, intrapsychic conflict, description of pain and response to previous modes of therapy. Such potential results will be compared with the results of other investigations to substantiate the relevance and rationale of this instrument. We hope that psychogenic pain individuals as compared to non psychogenic pain patients and controls endorse more frequently questions related to psychic conflict, significant anxiety before the onset of pain, depression, psychic trauma in infancy, psychosomatic and hypochondriacal trends, dependency and use of pain with manipulative purposes.

The 52 final items of the instrument are presented below:

$0=$ never $\quad 1=$ rarely $\quad 2$ = occasionally $\quad 3$ = frequently $\quad 4=$ always

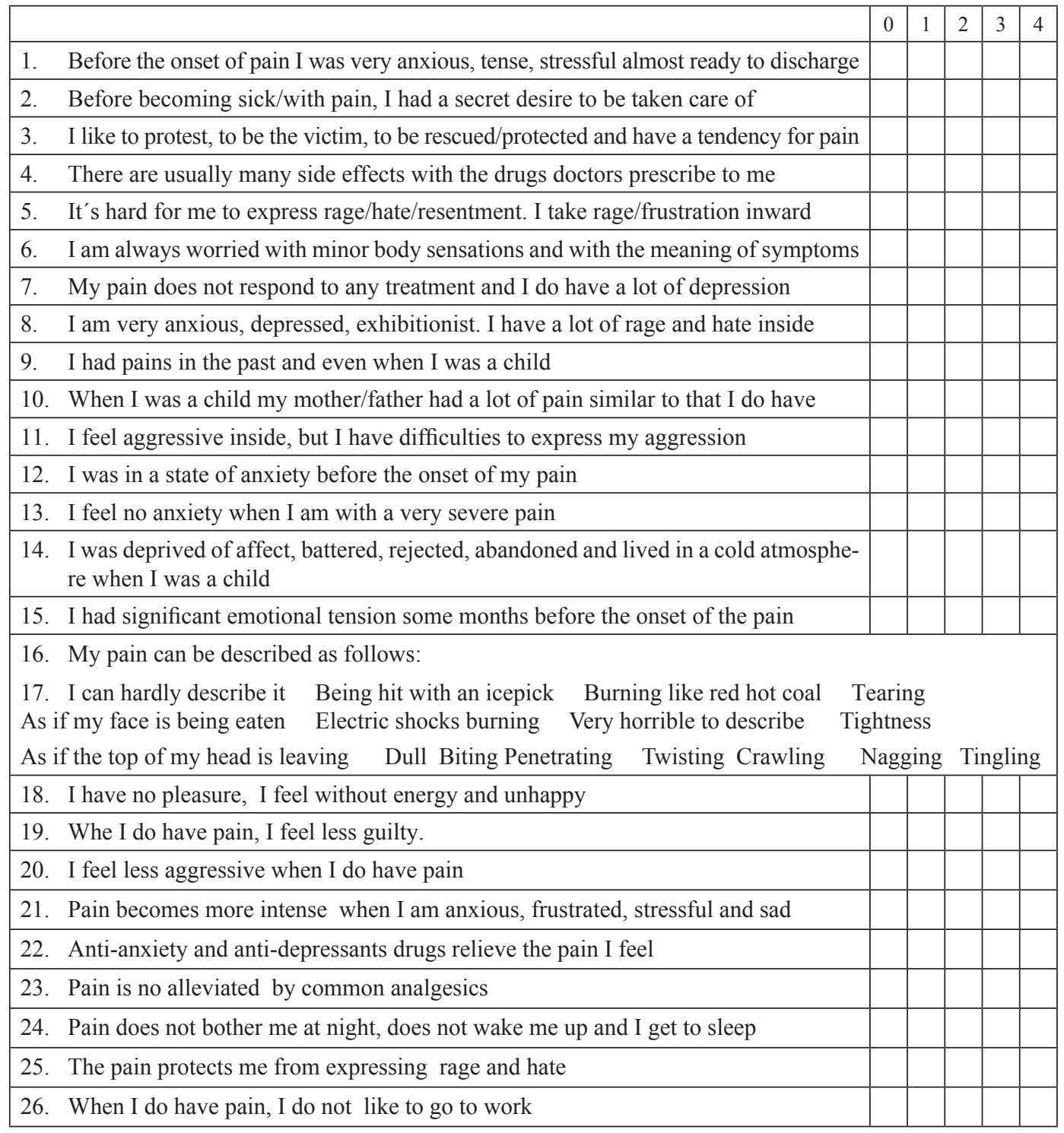




\begin{tabular}{|l|l|l|l|}
\hline 27. I use the pain to cause guilt in others & & & \\
\hline 28. I feel I use pain to punish myself & & & \\
\hline 29. I do have a lot of emotional problems and I need help from others & & & \\
\hline 30. I do have pain in many anatomic areas & & & \\
\hline 31. I am a very dependent, compulsive, aggressive and sufferer person & & & \\
\hline 32. My father/mother/grandfather/grandmother had pain in the same area of my pain & & & \\
\hline 33. Pain began following the birth of: & & & \\
\hline 34. Pain began following the death of: & & & \\
\hline 35. Pain began following separation of: & & & \\
\hline 36. Pain began following quarrels/arguments of: & & & \\
\hline 37. Pain began following psychological disorders in: & & & \\
\hline 38. Pain followed a disease in a member of the family: & & & \\
\hline 39. Pain began when I left home or my parents went away & & & \\
\hline 40. Pain initiated following a threatened/loss of important personal relationship: & & & \\
\hline 41. An important personal relationships is being threatened & & & \\
\hline 42. My mother was domineering/non affective/rigid, my father was calm and passive & & & \\
\hline 43. Many times I feel rage, then I feel guilty and then the pain comes & & & \\
\hline 44. My conflict is to joint with somebody and fear of being absorbed/engulfed & & & \\
\hline 45. I Am afraid of fusing physically/emotionally with somebody and being abandoned & & & \\
\hline 46. I fear to express rage, I feel guilty and I expect retaliation from others & & & \\
\hline 47. My family used to be worried and took more care of me when I was sick & & & \\
\hline 48. I observed sexual scenes when I was a child, and this bothered me a lot & & & \\
\hline 49. When I was a child I witnessed some violent acts in the family, I still think about it & & & \\
\hline 50. If I feel guilty is because I have somebody inside which punishes me & & & \\
\hline 51. When I was a child there was someone who was always punishing me & & & \\
\hline 52. There was somebody in the family which my mother/father was always punishing & & & \\
\hline
\end{tabular}

As for the clinical cases described below, patients were informed about the goals and objectives of this study, confidentiality was warranted, they were also informed about the benefits of this study, and signed an informed consent to participate.

Case 1: This is the case of a female patient 43 years old who presented for the first consultation for orofacial pain in February 2010. Her chief complaint was pain into the mouth, in the oral mucosa (corresponding to the roots of teeth 24 and 25), around her upper and lower lips, on the skin corresponding to the area innervated by the infra-orbital foramen, on both temporomandibular joints and very severe chronic headache pain. She had a history of previous surgical treatments on such teeth with limited success. She described her headache as bilateral, tightness, more severe in the left side, no nausea and vomiting, occurring almost every day and lasting hours or days with periodic exacerbations which did not respond to analgesics, anti-anxiety agents and/or antidepressant drugs. She was treated previously with a general clinician, three dental practitioners, one neurologist and an oral surgeon in different cities in northern Brazil with no satisfactory results. Following treatment with analgesics, electrical nerve stimulation, one oral splint, antidepressants and local anesthesia, she obtained relief for facial and TMJ pain, but her headache remained unchanged. She also presented with very severe bruxing behavior and other oral jaw habits. She scored very high on depression (BDI=28), anxiety (TMAS=21/28), hysteria (34/60), hypochondria (46/55) and guilt. Following encouragement to report stressful situations, anxiety and family life, she reported that she was abused emotionally when a child and reported significant conflicts with guilt, anxiety and repressed rage. Following application of a questionnaire to assess psychic conflict and psychogenic pain, the diagnosis of psychogenic facial and head pain was established, she was referred to a psychologist for proper treatment and she reported that her headache and facial pain improved markedly. 
Case 2: This is a case of a 40 years old young lady who presented for orofacial pain consultation in May 2011. Her chief complaint was pain in tooth 23 and frontal and temporal headache. The tooth pain was described as continuous and did not increase or could be reduced by cold or warm. Her tooth pain shifted regularly to the other side of the mouth and was described with the same quality and frequency as tooth 13 . There was neither a history of a tooth pathology which could explain pain in tooth 23 and 13, nor a history of previous treatments and current pathology in such teeth. Se also complained of facial and bilateral TMJ pain, but her major concern and worry was pain in the aforementioned teeth. All previous modes of therapy including analgesics, splints, counseling, heat and other therapies had failed. She also presented very severe bruxing behavior, other jaw habits and a number of complaints in other organs and systems of the body. Moreover, using Hiller's questionnaire, a diagnostic of somatization was established. She also scored very high in anxiety, hostility, hysteria and hypochondria. Splints, analgesics and even anti-anxiety agents provided no sufficient relief of her pain which seemed to be persecutory as she used to talk about her pain every time she entered the room for consultation, and curiously, she presented "la belle indifference".

It was only following the fourth consultation that the patient spontaneously and without any minor pressure revealed the presence of severe psychological conflicts in the family including conflicts with her husband and one son who she revealed became homosexual recently, a change she could neither understand nor bear. Pain in such teeth had become delusional, as although they were absolutely normal, she reported that some times there was pus in the bone root areas of both teeth. At a deeper level, the pain in the teeth represented abnormal relationships and unresolved conflicts with important family figures, specifically her husband and her son from whom she was very dependent. Pus in the teeth roots was interpreted that the base of the family relationship and dependency was in danger/or deteriorating. She was not able neither to understand nor to elaborate her deep rooted psychic conflicts and she had learned to internalize anger, thus becoming depressed, hopeless and helpless. A diagnosis of psychogenic pain was then established.
Case 3: This is the case of a 32 years old young lady who presented for the first time for consultation in the Dental and Medical School in August 2011. Her chief complaint was severe and chronic headache located in the occipital and sub-occipital areas of the head and related with chronic tension of the trapezius muscles, causing pressure on the greater and lesser occipital nerve. She alto reported another type of headache in the frontal and temporal areas of the head and chronic bilateral TMJ and facial pains. Both occipital and temporal+frontal headaches were very different in terms of description and mechanisms. She reported that her temporal and frontal headaches occurred with a frequency of seven attacks per week, and with a duration of about ten years. This headache pain was extremely unbearable and incapacitating and have not responded to many modes of therapy. Following in depth questioning and examination, we established the diagnosis of occipital neuralgia, and TMJ/ facial pain. She also presented with multiple complaints in many organs in the body, a number of oral jaw habits, and very severe bruxing behavior. She reported the use of a number of medications with limited success. She scored very high on psychological measures including depression $(\mathrm{BDI}=21)$, hostility $(\mathrm{HO}=27)$, anxiety (TMAS=16), Hysteria $(\mathrm{HY}=38)$, somatization $(\mathrm{SO}=17)$ and hypochondria $(\mathrm{HP}=29 / 55)$. She reported that her pain headache was exacerbated by stress and frustration. She also had deep seated psychological conflicts regarding guilt, dependency and rage. Splints, analgesics, electrical nerve stimulation, and local anesthesia used in combination were very effective to abolish her occipital neuralgia, TMJ and facial pain. Although she was very satisfied with the results of treatment for occipital neuralgia, TMJ and facial pain, her frontal and temporal headaches were not alleviated and remained unchanged and severe during two months of treatment for this and other pains. Following further inquiries about her infancy and family, and application of a recently developed questionnaire for psychic conflict, the diagnosis of psychogenic headache was established and she was referred for further evaluation and treatment. 


\section{Discussion}

\subsection{Destructive bruxing behavior}

All three patients with psychogenic pain in this study presented with destructive bruxing behavior and pain in other parts of the body. The outcome of the current study indicates that destructive bruxing behavior may be found in patients with psychogenic pain and somatization. Thus, the results of this study are in accordance with one investigation (16), reporting that all patients in the group with destructive bruxism presented with severe muscle and TMJ pain and complaints in other areas adjacent to the masticatory system. Additionally, another study (17), reported that frequent or more severe bruxers complained more frequently of facial pain, headache, neckaches and backaches. Additional support for the results in the current study comes from one investigation in TMD patients (18), reporting that most patients were involved in chronic problems in their lives. As their rage and resentment increased, they had an additional need to control their rage which was channeled to severe bruxing behavior indicating that severer bruxism is more likely to be found in TMD cases with severe pain and psychiatric disorders.

\subsection{Unsuccessful modes of therapy}

Patients in this study reported unsatisfactory results following the use of many modes of therapy including analgesics, antidepressants, anti-inflammatory drugs, splints and counseling. Thus, the results of this investigation are in line with the results of the review of the literature (2), indicating that most modes of therapy for chronic headaches were ineffective with the exception of antidepressants. It may be that patients in this study had been subjected to different modes of therapy used not in conjunction but rather, at different times and in insufficient dosages. Supporting this line of reasoning, one study (2), asserts that therapeutic failure may be associated with the use of a small dose for a short period of time. It may also be that psychogenic facial pain or headache is closely associated with depression, and antidepressants are not used frequently in the treatment of such patients. Psychogenic pain is not usually relieved by analgesic medication (9). It may be that because psychogenic pain is mostly caused by dynamic mechanisms in the psychic apparatus, pain does not respond to the usual modes of treatment recommended in other organic disorders. This point of view has support in one study (1), indicating that patients with psychogenic orofacial pain have had negative experiences of treatment: Surgery has often failed, drugs have not worked and numerous laboratory investigations have given normal results.

\subsection{Severe psychological disorders}

All cases reported in this study presented with severe psychological disorders including anxiety, depression, and somatization. Thus, the results of this study are in accordance with one investigation (18) in a subgroup of TMD patients presenting with severe pain, severe bruxism and psychiatric disorders including anxiety, somatization, rage, resentment and psychic conflict. Kampe and coworkers (17), reported that compared to less frequent bruxers and the general population, the more frequent bruxers presented higher scores in the somatic anxiety, the muscular tension and in the psychic anxiety scales indicating that they were more vulnerable to anxiety, muscle tension and psychosomatic disorders. Additionally, one recent study (19), reported higher scores for anxiety, hysteria, somatization and hostility in severe and extreme bruxing behavior with facial pains and headaches. Additionally, MPD patients with facial pain non responding to conventional therapy showed a greater overall degree of emotional distress. Some patients are inclined to hysterical character marked by repression and somatization (20). Some individuals with psychogenic pain are chronically depressed, pessimistic and feel guilty (10). Increasing pain severity, pain that interferes with daily activities, frequent pain episodes, diffuse pain, and pain that is refractory to treatment, are all associated with more severe depressive symptoms (21). 


\subsection{Combination headaches or pains}

Patients in this study presented different combinations of headaches and or facial pains. Case one complained of pain in the mouth, lips, infra-orbital area and headache. The Chief complaints in case two were toothache and frontal and temporal headache and case 3 presented with severe occipital and sub-occipital pain, frontal and temporal headache, cervical and TMJ pain. Thus, various pain types in different anatomic areas can be observed in patients presenting with psychogenic pain. Because all patients with psychogenic pain in this study presented with a complaint of headaches, the results of this study have support in one investigation (2) about psychological aspects of headache reporting that headache may be an important symptom in most forms of psychiatric illness and in many cases it can be the presenting complaint. The results of this study are also in accordance with one investigation (3), indicating that the most common areas with pain in individuals with psychogenic pain are the head and neck. Taking into account that the head and face constitute only a small part of the body and that patients in this investigation presented with many pain complaints, the results of this study are in line with one investigation (9) indicating that psychogenic pain occurs in multiples sites and extends over an increasing area. Because patients in this study scored higher in somatization and reported multiple complaints in a restricted area of the body (head and face), the results of this study have additional support in one investigation (22), carried out in unexplained orofacial pain patients reporting that pain in those individuals was more likely to occur in different anatomic sites.

\subsection{Severe pain}

Severe, intractable pain was reported by all three patients in this study. Because patients in this research reported severe chronic pain, higher scores in somatization were found and all were depressed, the results of this investigation have support in one study (21), indicating that patients with pain and co-morbid depression experience more pain complaints, more intense pain, more amplification of pain symptoms and longer duration of pain. Severe pain and disability may be two characteristics of chronic psychogenic pain (23). Severe and persistent pain can be entirely of emotional origin and can respond completely to psychiatric treatment (3). In one study (22) subjects with unexplained facial pain were more likely to report higher levels of overall disability, psychological distress and severer pain as compared to dental pain patients.

\subsection{Psychic conflict}

All three patients in this study reported psychic conflict centered around difficulties to express rage, resentment, guilt and strong dependency needs. Psychic conflict in severe bruxers with persistent pain and in patients presenting with psychogenic pain has been reported in a number of studies $(8,10,18)$. All patients in this study reported headaches, thus, the results of this investigation are in line with one research (2), reporting that in the case of depression and psychogenic headache, pain may sometimes be a symptom equivalent for anxiety and for other emotional conflicts and relief of psychogenic headache can be obtained after locating such emotional conflict which is then resolved by discussion. In a study of cases presenting with both severe temporomandibular disorder patients and bruxism, psychiatric disorders were conspicuous an anxiety was associated with psychosomatic disorders (18). As rage and resentment associated with a deep rooted conflict increased in such patients, rage was channeled to the teeth resulting in many complaints of pain (18). Engels (8), evaluated many "pain prone patients" and reported that "in their choice of pain as the symptom, a long-term background of guilt could be found in such patients". Thus, it seems apparent that in many patients with psychogenic pain, guilt blocks the expression of rage and resentment. Conflict in patients with chronic psychogenic pain usually involves family members, most often spouse or parents and repressed anger and hostility are the base of such conflict (23). In the "pain prone patient", psychogenic pain may have different meanings including expiation of guilt, identification with the 
aggressor, identification with a parental figure, a symptom representing repressed aggression for fear of retaliation and fear of losing an important parental figure from which the patient is dependent (8). Many other meanings can be attributed to pain in individuals presenting with psychogenic pain.

\section{Conclusions}

Based on the descriptions of these clinical cases, and backed by the review of the literature on psychogenic pain, some conclusions can be drawn:

1. Various types of other pains may occur in subjects with psychogenic face and head pain;

2. Psychogenic pain individuals usually present severe pain associated with depression.

3. Psychic conflict, somatization and depression are usually associated with psychogenic pain.

4. Severer bruxing behavior types are more likely to be found in patients with psychogenic pain and it is clear that such severity is related to difficulties to channel rage outward.

\section{References}

1. Hunter, S. The management of psychogenic orofacial pain. British Medical Journal,v.304, p.330-331, 1992.

2. Bridges,P.K. Psychological aspects of headache. Postgraduate Medical Journal, v.47, p.556-561, 1971.

3. Lo, W.H. Psychogenic regional pain. The Bulletin of the Hong Kong Medical Association, v.20, p.63-68, 1968.

4. Benbadi, S.R. Association between chronic pain or fibromyalgia and psychogenic seizures. AJPM, v.15, p.117-119, 2005.

5. Ruden, R.A. A neurological basis for the observed peripheral modulation of emotional responses. Traumatology, v.11, p.145-158, 2005.
6. Weatherhead, A.D. Headache associated with psychiatric disorders: Classification and etiology. Psychosomatics, v.21, p.832-840, 1980.

7. Abdul Rahman, Z.A. The etiology and management of chronic idiopathic facial pain: A review. Annals of Dentistry, University of Malaya, v.5, p.40-44, 1998.

8. Engel, G.L. Psychogenic pain and the pain-prone patient. American Journal of Medicine, v.June, p.899-918, 1959.

9. Lim, L.E. Psychogenic pain, Singapore Medical Journal, v.35, p.519-0522, 1994.

10. Adler R, H.; Zlot, S.; Hürny, C.; Minder, C. Engel's psychogenic pain and the painprone patient: A retrospective, controlled clinical study. Psychosomatic Medicine,

11. Violon, A. The onset of facial pain. Psychotherapy and Psychosomatics, v.34, p.11-16, 1980.

12. Durhan, J.; Exley, C.; Wassell, R.; Steele, G.J. Management is a black art. Professional ideologies with respect to temporomandibular disorders. British Dental Journal, v.202, p.E29, 2007.

13. Pfaffenrath, V.; Rath, M.; Pollman, W.; Kieser, J.M. Atypical facial pain: Application of the HIS criteria in a clinical sample. Cephalalgia, v.13, p.84-88, 1993.

14. Hurwitz, T. Somatization and conversion disorder. Canadian Journal of Psychiatry, v.49, p.172-178, 2004.

15. Fishbain, P.; Cutler, R.B.; Rosomoff, H.L.; Rosomoff, R. Do antidepressants have an analgesic effect in psychogenic pain and somatoform pain disorders? Psychosomatic Medicine, v.60, p.503-509, 1998.

16. Ware, J.C.; Rugh, J.D. Destructive bruxism: Sleep stage relationships. Sleep, 1988; 11: 172-181. 
17. Kampe, T.; Edman, G.; Bader, G.; Tagdae, T.; Karlsson, S. Personality traits in a group of subjects with long-standing bruxing behavior. Journal of Oral Rehabilitation, v.24, p.588-593, 1997.

18. Moulton, R.E. Oral manifestations of anxiety. Psychiatry, v.18, p.261-273, 1955.

19. Molina, O.F.; Peixoto, M.G.; Santos, Z.C.; Penoni, J.; Aquilino, R.; Peixoto, M. Bruxism as a mechanism subserving hysteria: A new theory. Revista Neurociências, v.16, p.262-268, 2008.

20. Schwartz, R.A.; Greene, C.S.; Laskin, D.M.; Personality characteristics of patients with myofascial paindysfunctions syndrome unresponsive to conventional therapy. Journal Dental Research, v.58, p.1435-1439, 1979.
21. Bair, M.J.; Robinson, R.L.; Katon, W.; Kroenke, K. Depression and pain co-morbidity. American Medical Association, v.163; p.2433-2445, 2003.

22. Aggarwal, V.R.; McBeth, J.; Zakrzewska, J.M.; Lunt, M.; Macfarlane, G.J. The epidemiology of chronic syndromes that are frequently unexplained: do they have common associated factors? International Journal Epidemiology, v.35, p.468-476, 2006.

23. Sarno, J.E. Chronic back pain and psychic conflict. Scandinavian Journal of Rehabilitation Medicine, v.8, p.143-153, 1976.
Endereço para Correspondência:

Omar Franklin Molina DDS, MDS, PA

ofrank.nyork.harvard.texas@hotmail.com

Avenida Pará, 1544

Gurupi - T0

CEP: 77400-020 